Ananny, M., Strohecker, C. \& K. Biddick (In Press). Shifting Scales on Common Ground: Developing Personal Expressions and Public Opinions. International Journal of Continuing Engineering

Education and Life-Long Learning.

\title{
Shifting Scales on Common Ground: Developing Personal Expressions and Public Opinions
}

\author{
Mike Ananny ${ }^{1}$, Carol Strohecker ${ }^{1}$, Kathleen Biddick ${ }^{2}$ \\ ${ }^{1}$ Everyday Learning, Media Lab Europe \\ Sugar House Lane, Bellevue, Dublin-8, Ireland \\ \{ananny, stro\}@medialabeurope.org \\ ${ }^{2}$ Department of History, University of Notre Dame \\ Notre Dame, IN 46556, USA \\ biddick.1@nd.edu
}

Since no embodied speaker can produce more than a partial account, and since the process of producing meaning is necessarily collective, everyone's account within a specified community needs to be encouraged. - Linda Alcoff, 1995 [1]

\begin{abstract}
We present an approach and a tool for helping individuals express small story-like expressions of personal perspectives in the context of larger, collage-like incubators of public opinions. Our goal is to work with people to create technologically supported public discourse spheres in which they can both represent personal views and practise new ways of forming collective opinions. We present the design and use of one public sphere system, TexTales, a large-scale photographic installation to which people can send SMS text message captions. We review one community's experiences with TexTales, and discuss the insights we gained about how residents scale and ground their civic discourse and move between expressions of individual perspectives and public opinions.
\end{abstract}

Keywords: public opinion, civic discourse, multimodal interfaces, intermodal literacies, SMS text, interactive community projection, citizen journalism.

\section{Introduction}

Civic discourse is, in a sense, like storytelling. Public spheres - from kitchens to Internet chat rooms - are filled with people experimenting with ideas, practising arguments and learning from each other by trading perspectives through narrative. As these stories are constructed in - and, in turn help to construct - public spheres, they become both expressions of individual perspectives and the building blocks of public opinions. It is in these spaces that distinctions between good citizens, good storytellers and good learners blur as participants practise a kind of communicative dexterity, moving among a variety of views, roles and scales. Our principal contribution is a way for individuals and communities to form both new opinions and new ways of forming opinions. Our aim is to develop public spheres that explicitly support the development of multiple perspectives through a plurality of voices and expressive modalities.

Our goal is not to develop better ways of measuring public opinion, nor is it to connect citizens to their governments nor is it even to create new kinds of consensus. Rather, we aim to better understand the nature of public opinions and how they emerge from negotiations of individual perspectives. We do this following Constructionist design methods [10,12], working with people to create new public spheres that become "objects to think with" [11] as they consider the materials and activities of their civic discourse, what kinds of opinions they and their neighbours hold and how they came to form these opinions. This emphasis on socially situated and technologically supported construction leads to a three-part focus on who participates in public spheres, what kinds of tools and techniques people use to practise civic discourse and how public opinions emerge from smaller-scale conversation. In particular, we 
Ananny, M., Strohecker, C. \& K. Biddick (In Press). Shifting Scales on Common Ground: Developing Personal Expressions and Public Opinions. International Journal of Continuing Engineering Education and Life-Long Learning.

work with people to create new tools and methods for moving between small, story-like expressions of personal views and larger, collage-like incubators of public opinion.

Here we present one system, TexTales [3], created to support and investigate authorship at varying scales and in everyday spaces that become new forums for public discourse. TexTales is a large-scale photographic installation to which people can send SMS text captions from mobile phones. We review one community's experiences designing a TexTales installation. Analysis of the resulting archive reveals novel personal expressions, broad communications trends and implications for new means of forming and polling public opinions.

Figure 1. Left: The TexTales interface with 9 images and, for each image, the three most recently sent SMS text captions. Right: a TexTales installation in Dublin's Fatima Mansions community.

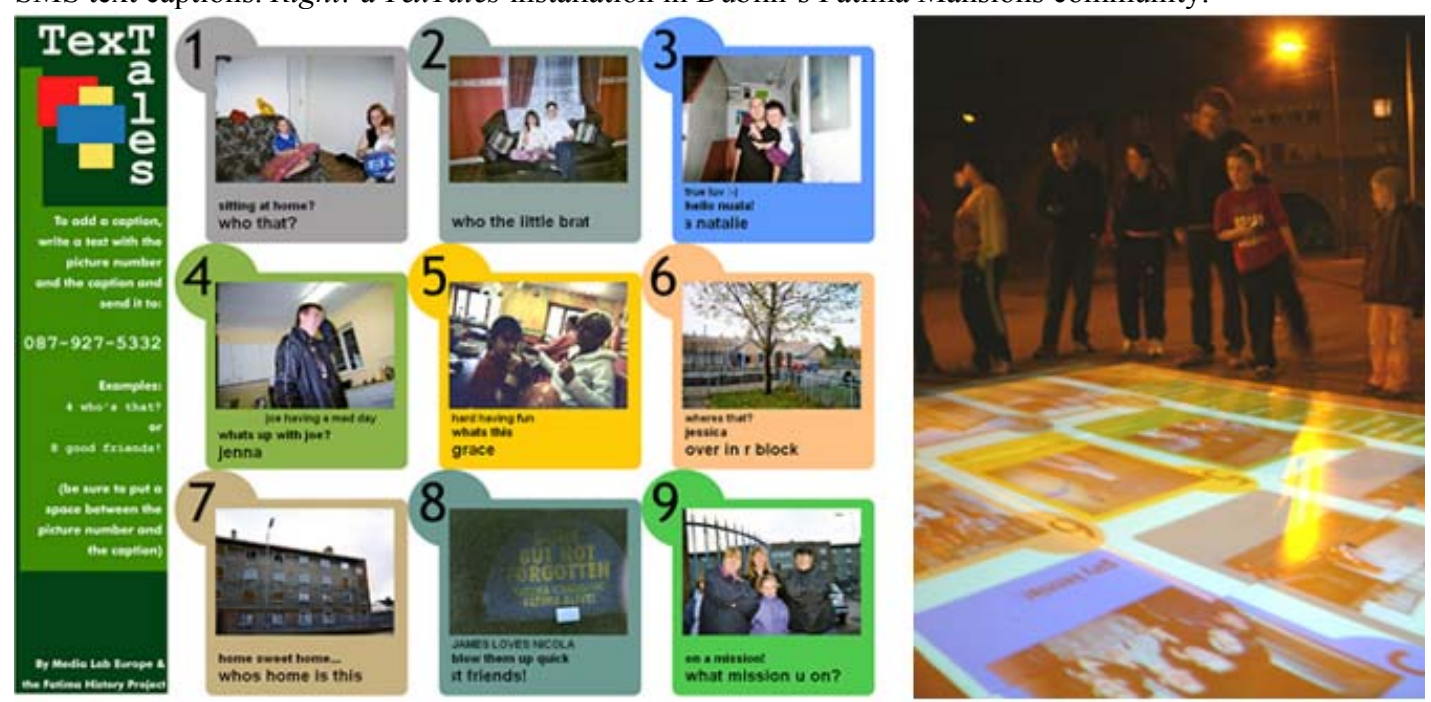

Towards a Developmental Model of Civic Discourse

The kinds of skills practised while constructing narratives are akin to those involved in constructing public opinion: imagining an audience you may never get to meet; reflecting and revising both the form and content of your message in response to feedback; and creating communications artefacts intended to represent a perspective long after an author may be gone.

Beyond these broad similarities, we see two central tensions emerge when we consider narrative in relation to public discourse. The first has to do with who authors and hears the stories, namely finding a balance between narratives created for personal scales versus narratives created for collective scales. If people are to frame and develop public opinions using narrative forms, there need to be ways to balance narratives as expressions of personal views with public opinions as large-scale representations of broad perspectives. In essence, stories are good carriers of both personal experiences and universal conditions but, if they are to co-exist with quantitative and statistical measures of public opinion, the individuals creating and aggregating narratives need to become adept at thinking about what and who a story is representing. Whenever we consider how a single narrative perspective is a compelling example of a broader trend, we need to be aware of issues of rhetoric, power and representation.

The second tension has to do with the nature of the narratives themselves, namely finding a balance between stories that are highly contextual versus stories that have broad appeal. If public sphere stories are to be more than anecdotal inferiors to more formalized, quantified 
Ananny, M., Strohecker, C. \& K. Biddick (In Press). Shifting Scales on Common Ground: Developing Personal Expressions and Public Opinions. International Journal of Continuing Engineering

Education and Life-Long Learning.

representations of public opinion, citizen authors need to be aware of both the power and limitations of creating narratives that are highly personal and context-specific. In a sense, if views are to become starters for larger-scale discourse, authors need to consider how their perspectives are "grounded" [6].

There is growing discourse among political communications scholars about who can represent people, and at what demographic scales and through what organizational means models of democratic discourse best operate. Peters [13] argues that there is a tension between using objective, impartial quantifications which aim to ensure democratic equality while still acknowledging that democratic processes consist of personal values, feelings, perspectives and stances and that stories are one way to represent them. Schudson $[15,16]$ takes a historical perspective, focussing on concrete examples of personal participation in democratic activities such as voting and membership in political parties. He also analyses the places in which people have practised civic discourse, such as traditional townhall meetings, and argues that not all conversation is of a democratic nature: "what distinguishes democractic conversation ... is not equality, but publicness ... it is profoundly uncomfortable." [14, emphasis in original]. Asen [4], in re-interpreting John Dewey's [7] ideas on democracy in relation to modern political communications, highlights the need for us to consider the means by which people move among multiple public spheres, public and private stances and local, face-to-face interactions versus mobile settings.

Human-computer interface researchers and designers have also been considering new spaces and technologies for supporting community and social activities. Brignull and Rogers [5] specifically focus on overcoming people's resistance to participating in open spaces with large-scale displays, identifying social embarrassment as a principal barrier to participation. Unlike their Opinionizer system in which participants input comments via a laptop, TexTales supports multiple points of user input via mobile phones. People may feel more comfortable participating in a public discourse space if they do not have to use a single terminal in a single place of participation and if the input device is one they are already familiar with. TexTales relies on people's existing familiarity with their mobile phones and does not require people to use a single input terminal in a single place of participation. Perhaps some of people's embarrassment will be alleviated if they can participate anonymously with a comfortable, known technology that supports a variety of rich and familiar interaction modalities.

Grinter and Eldridge [8,9] show texting among teenagers to be an evolving medium that is economically viable and that consists of a unique short-form "language". They also found that teenagers' tend to have one-to-one conversations via texting, not simultaneous, multithreaded discourse. TexTales participants in this study did seem to engage in simultaneous texting, sending captions to more than one picture and managing several caption threads at once. This seems to indicate the presence of a different kind of "thread" than the one Grinter and Eldridge consider. Their texting threads were among single, distributed users with personal mobile phones whereas the threads we saw with TexTales were among multiple users around a shared interface. Some users even shared mobile phones.

For stories to move from being expressions of individual threads and perspectives to building blocks of public opinions, there need to be ways for people to experiment with creating linguistic "chunks" that start and sustain public discourse. We think these have to be authored in ways that are:

Varied: people should be able to author in a variety of media, experimenting with different styles of expression and new forms of hybrid visual-textual chunking

Scalable: people should be able to author chunks that start and continue public sphere discourse and that let them move among roles of author/audience, participant/observer, representative/constituent 
Ananny, M., Strohecker, C. \& K. Biddick (In Press). Shifting Scales on Common Ground: Developing Personal Expressions and Public Opinions. International Journal of Continuing Engineering

Education and Life-Long Learning.

Accessible: people should be able to participate in a variety of public spheres through common tools and activities that do not require specialised expertise but that do offer opportunities to develop personal styles

Relational: people should be able to create chunks for individuals, small groups or broad audiences, helping individuals establish a variety of relationships with different people, many of whom an author may never meet

Transparent: people should be able to create chunks that show the history and context of a contribution, helping other public sphere participants understand and debate a perspective's provenance

This model raises interesting representational questions that guide our discussion of TexTales' design and use. What forms might perspectives take? How do they develop with respect to social contexts? What do we learn about peoples' civic literacies as they experiment with different tools and techniques for public sphere discourse? Finally, and of particular interest to epistemologists interested in civic discourse, how can these representations take transparent forms that give both authors and audiences ways to see perspectives and opinions develop?

This model is an aspect of a larger, on-going effort we are engaged in called "Citizen Journalism" [2] in which we consider the tools, relationships and broadcast mechanisms by which individuals with no formalized training in journalism can share perspectives by authoring stories for broad audiences. At the heart of this issue - and its relevance to the issues that frame TexTales' development - is the notion that, as new multimodal communications technologies become more broadly accessible, processes for creating and debating perspectives and opinions will become more visible. People will need facility with different kinds of learning, storytelling and citizenship skills that emphasize movement among and dexterity within a variety of public discourse spheres.

Below we describe the design and use of TexTales and discuss how it is helping us understand how people develop both personal expressions and public opinions.

\section{Designing Public Spheres: TexTales and Fatima Mansions}

We recently underwent a 6-month design process with a community called Fatima Mansions, an urban apartment complex near our lab in Dublin, Ireland. (For a more extensive description of the design process and TexTales technical architecture, see [3].) Fatima is a community of approximately 700 residents living in 14 4-story apartment buildings in an area of Dublin traditionally labelled as "disadvantaged" by the Irish government. We worked with a history group over a period of 6 months to take, select and prepare images for a TexTales installation.

We first distributed disposable cameras in the community and, in collaboration with professors and students at Loyalist College Canada's Photojournalism programme, asked residents questions, like "show me something you love," "show my something about your community you'd like to change," "show me something you'd like someone standing here 100 years from now to see." Few participants followed these questions strictly but instead saw them as broad starting points for thinking about how to describe their community. Residents took over 700 images. The history group then meet regularly to edit and arrange these images into TexTales interfaces, selecting images that they felt were somehow relevant to and representative of the broad community and creating 10 TexTales interfaces for installation in the community.

We installed TexTales in Fatima Mansions for 3 nights, each installation lasting approximately 2 hours per night. The participants were primarily residents of Fatima with 
Ananny, M., Strohecker, C. \& K. Biddick (In Press). Shifting Scales on Common Ground: Developing Personal Expressions and Public Opinions. International Journal of Continuing Engineering Education and Life-Long Learning.

minor participation by visiting researchers and people from outside the community. Flyers were distributed around the community advertising the installation and many people approached based on that advertisement. While not explicitly designed for children, young people were the primary participants, contributing the most texts and staying with the installation for the longest, some for the entire time over all three nights.

Figure 2. Top: The Fatima History Group editing images taken by Fatima residents. Bottom: Images from the installations at Fatima Mansions showing experiments with both ground and wall projections.
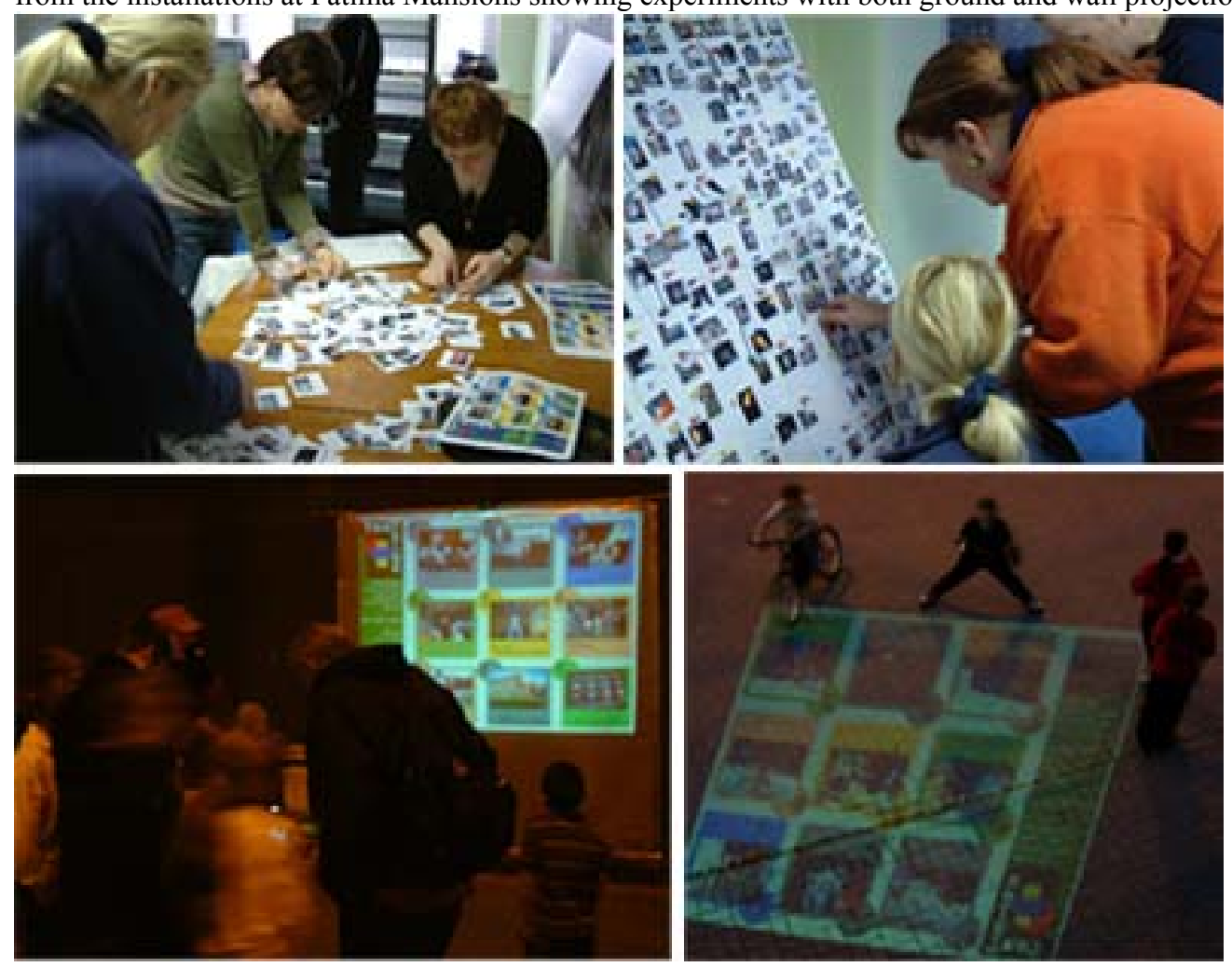

The installation was initially projected onto the ground from an adjacent building. This arrangement afforded several interesting full-body interactions with the images and the texts. Participants frequently walked around (and across!) the installation, crouching near parts of it and gathering in small groups around various parts of the projection. Unfortunately, the projection surface, the threat of inclement weather and severe keystoning of the projection necessitated a wall projection on the two subsequent nights. All installations were situated in a large square through which people pass as they enter and leave Fatima Mansions.

For each message sent to TexTales, the system automatically logs: the time and date the message was sent; the phone number from which the message was sent; the caption; and the photo to which the caption refers. For privacy reasons, the phone numbers in all log files presented here have been edited slightly but a way that still distinguishes different contributing phones. Many phone numbers appear more than once but should not be thought of as representing a single individual; for all 3 installations, mobile phones were shared among many participants.

The history group was also concerned that participants might send inappropriate or embarrassing texts but after discussing different options, we decided not to implement any kind of filtering system, seeing such systems are rarely effective, easily subverted and contrary to spirit of the work. We did ensure that anyone who appeared in an image understood this decision and consented to their picture being displayed. 
Ananny, M., Strohecker, C. \& K. Biddick (In Press). Shifting Scales on Common Ground: Developing Personal Expressions and Public Opinions. International Journal of Continuing Engineering

Education and Life-Long Learning.

\section{Analytical Methods}

In thinking about the "results" of the TexTales installation, our aim is to consider several questions, primarily focusing on the tensions articulated early, related to grounding and scaling. We use Clark's concept of discourse "grounding" in which conversants establish common ground through references to past conversations, immediate surroundings and shared cultural experiences [6]. One of our interests is in characterizing the kind of groundings TexTales' participants used among texts and within text-image combinations, looking for both broad discourse patterns and compelling special cases.

In setting up the analysis of scaling, our interest is in how conversational discourse occurred in the interface and how images and texts became elicitors for broader discussion. How do small-scale, individual contributions serve as starting points for larger, more in-depth discourse and how do people use both text and image to start and sustain conversation? Other questions include: what kinds of image-text combinations seemed "closest" or most mutually referential? How did individuals express ownership of the installation?

The number of texts sent to TexTales over the 3 nights (151) is too small for a statistically significant sample and, in fact, our aim is not to argue for any kind of repeatable phenomenon. Instead, we see the discussion of these results and even the choice of discourse categories as specific to the Fatima installations. The experiences with TexTales described here are very much specific to the individuals who took, appeared in and selected the installations' pictures and the individuals who observed and participated in the 3 installations. Their presence and contributions constitute a unique public sphere. Our goal is to better understand the nature of this experience with an eye toward, over time and other installations, observing how individuals and communities create and manage their unique public spheres.

\section{Macro Analysis of Texting Patterns}

After the installations, our first step was to categorise all texts into at least one of the following 8 groups. Our goal with this categorization was two-fold. First it was a reflective activity that helped us see how people were using TexTales generally, what kinds of uses seemed to be most prevalent and what kinds of broad categorizations, if any, make sense for such data. Second, it helped us focus on specific instances of image-texts combinations that we think illustrate novel uses of both public sphere discourse and the TexTales system with specific respect to the phenomena of grounding and scaling discussed earlier. Table 1 explains each category.

Table 1. Categories of Texting

\begin{tabular}{|r|l|}
\hline Picture reference & $\begin{array}{l}\text { Text refers to the picture in some way, for example, a person, } \\
\text { place or event contained in the picture }\end{array}$ \\
\hline Conversational - starting & $\begin{array}{l}\text { Text has a dialogic form, is not addressing an earlier text and } \\
\text { is explicitly inviting a response (e.g. explicitly asking a } \\
\text { question or inviting a response) }\end{array}$ \\
\hline Conversational - continuing & $\begin{array}{l}\text { Text has a dialogic form and is continuing an earlier } \\
\text { conversational text (e.g. answering a question posed earlier) }\end{array}$ \\
\hline Signed & Text is attributed or signed by its author \\
\hline Comment & $\begin{array}{l}\text { Text refers explicitly to a person who may or may not be in the } \\
\text { picture. }\end{array}$ \\
\hline Graffiti & Text makes an explicit statement, expressing an opinion \\
\hline Place reference & Text refers to a place which may or may not be in the picture \\
\hline
\end{tabular}

The Fatima History group prepared a total of 10 TexTales interfaces (90 pictures in total). During each evening's installation, all 10 interfaces were shown with some image sets eliciting far more texts than others. Figure 3 illustrates the trends across all 10 interfaces, showing the percentage of texts sent to the system that contained at least one of the features described in Table 1. Figure 4 illustrates the trends for the 5 interfaces that received the most 
Ananny, M., Strohecker, C. \& K. Biddick (In Press). Shifting Scales on Common Ground: Developing Personal Expressions and Public Opinions. International Journal of Continuing Engineering

Education and Life-Long Learning.

texts. Categorizations are not mutually exclusive: a text may be in more than one discourse category.

Figure 3. For all 10 interfaces, the percentage of texts containing a particular discourse feature are presented below. Note that the categories are not mutually exclusive (most texts fell into more than one category) and that the same general trends seen here also appear in Figure 4.

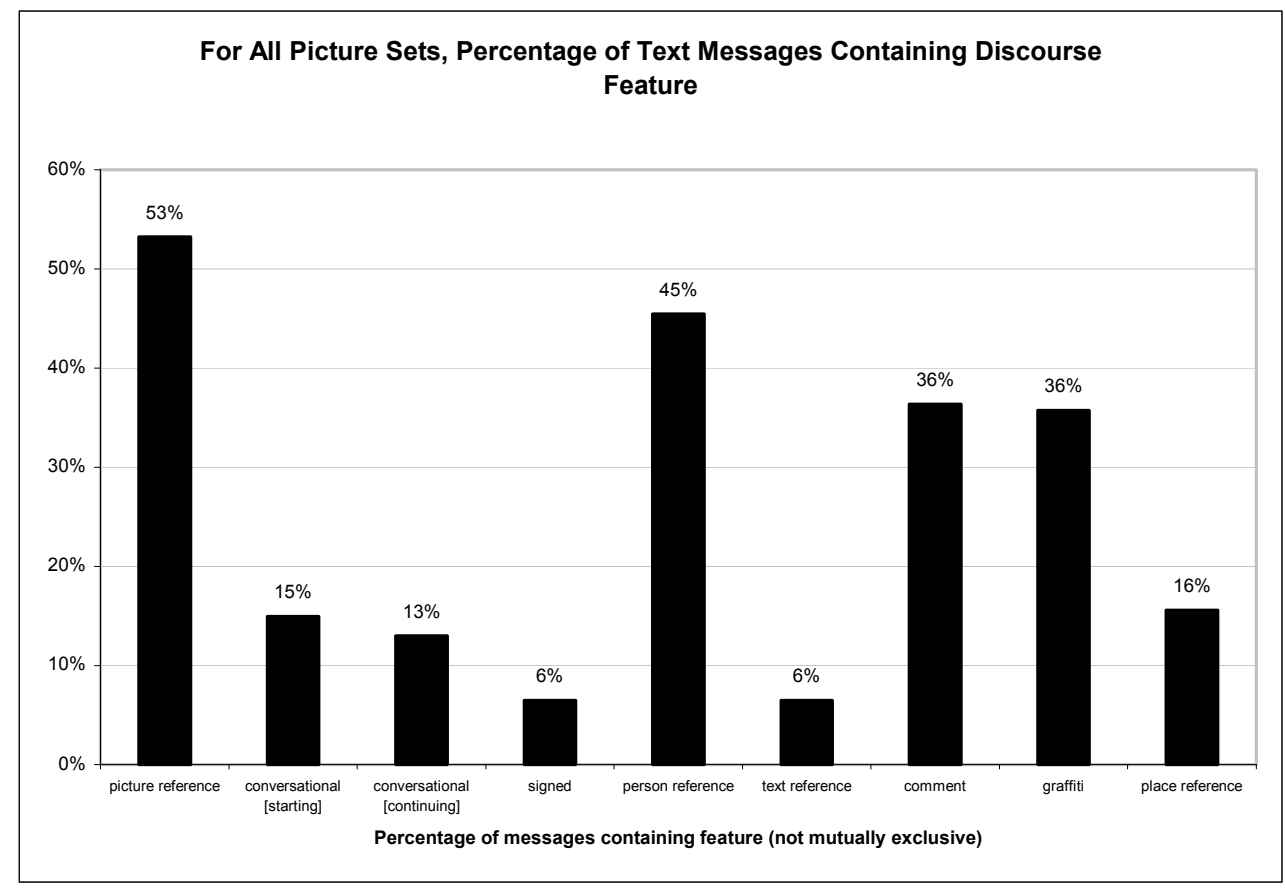

Figure 4. For each of the 5 interfaces that received the most texts, the percentage of texts containing a discourse feature. As in Figure 3, the categories are not mutually exclusive (most texts fell into more than one category). Note that that the trends seen in the breakdowns of the image sets are also seen in the Figure 3's representation across all image sets.

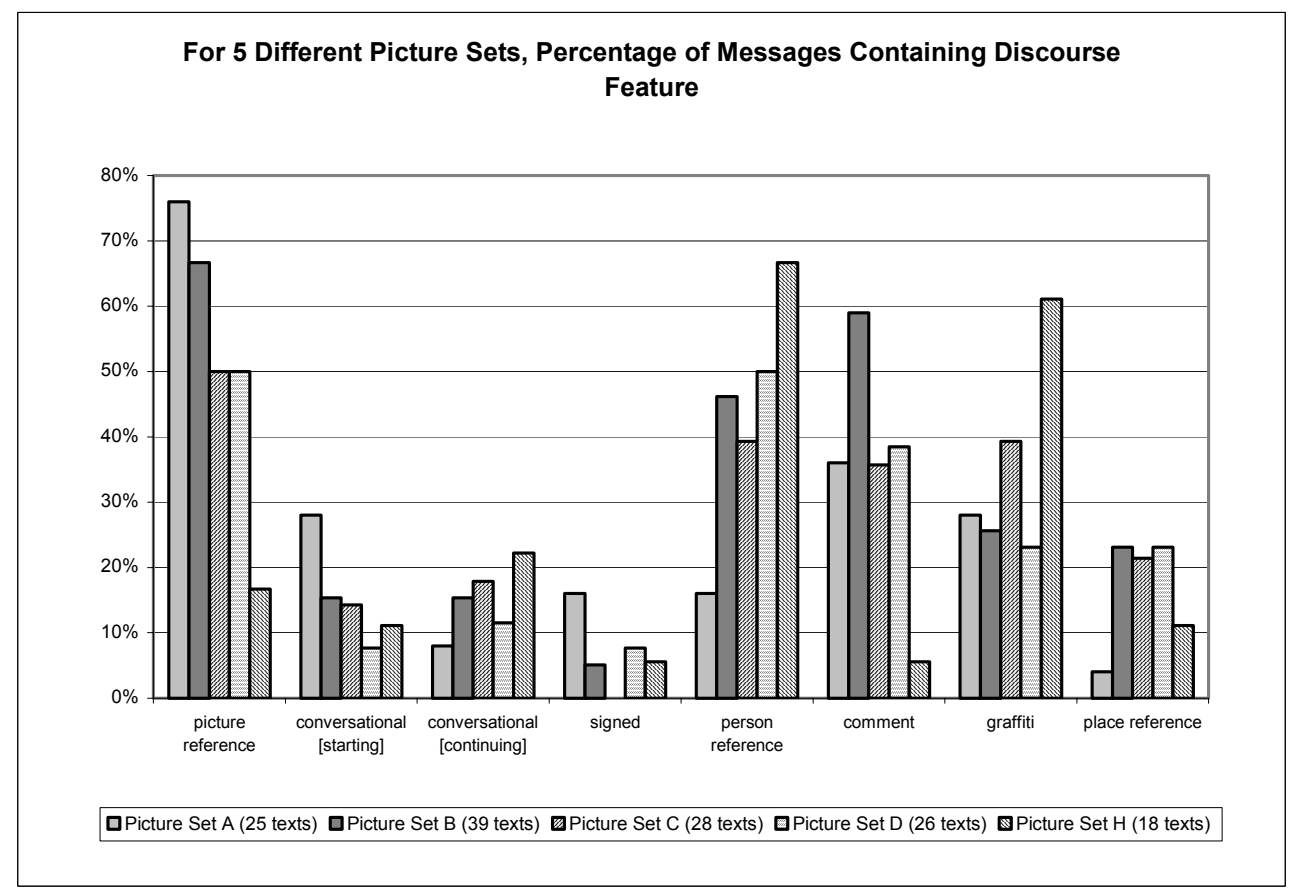


Ananny, M., Strohecker, C. \& K. Biddick (In Press). Shifting Scales on Common Ground: Developing Personal Expressions and Public Opinions. International Journal of Continuing Engineering

Education and Life-Long Learning.

\section{Archive Structure and Analytic Narratives}

From the 10 TexTales interfaces prepared by the history group, 3 serve as good starting points for discussing how the installations supported the grounding and scaling of public sphere discourse. Below, we present each of the 3 image sets, the complete log file for all texts sent over the 3 nights of installation and, for certain image-text combinations, more detailed analyses. We present these interpretations as "analytic narratives" that describe the texts in relation to both the images and the larger social context.

In addition to looking at these examples in relation to discourse grounding and scaling, we are also interested in whether they show people engaged in the casual, complex and diverse perspective-trading and opinion-making we outlined in our model of developmental civic discourse. In design language, is TexTales a "low-threshold, high-ceiling" [11] system that offers people different ways to enter and powerful ways to experiment?

Figure 5. Image Set B.

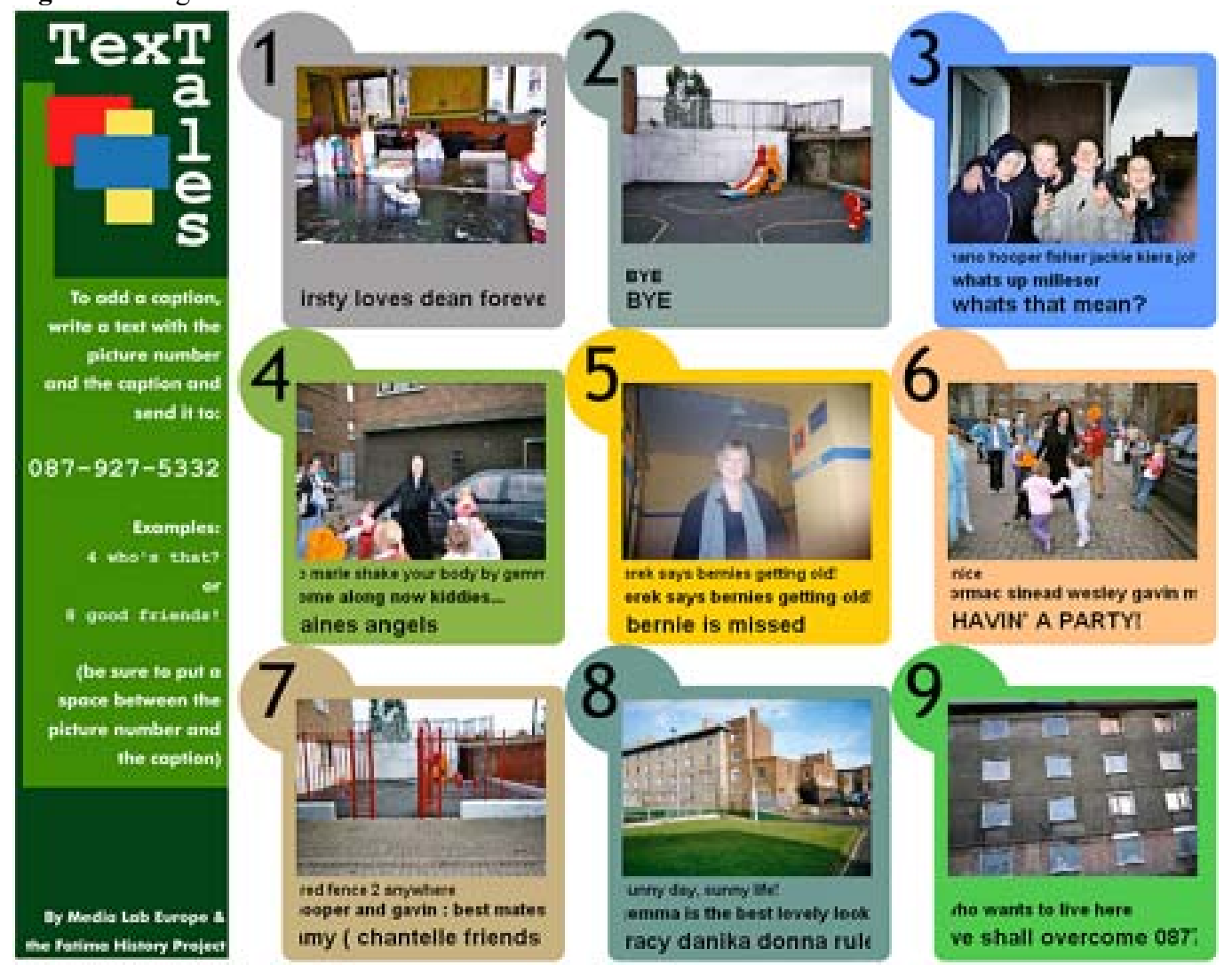

Table 2. All texts sent to Image Set B over 3 nights of installation, sorted by photo number. Image-text combinations for photos 2, 5 and 7 are highlighted and analysed below in more detail.

\begin{tabular}{|c|c|l|c|}
\hline Sender's Phone \# & Photo & \multicolumn{1}{|c|}{ SMS Text Caption } & Date, Time \\
\hline$+35387 \times \times \times 4359$ & 1 & kirsty loves deanforever & $03 / 05 / 09,21: 47: 48$ \\
\hline$+35387 \times \times \times 4519$ & 2 & where's that? & $03 / 05 / 09,21: 43: 34$ \\
\hline$+35386 \times \times \times 5794$ & 2 & very small playground & $03 / 05 / 09,21: 45: 21$ \\
\hline$+35386 \times \times \times 5794$ & 2 & terrys playground! & $03 / 05 / 09,21: 49: 15$ \\
\hline$+35387 \times \times \times 4519$ & 2 & FIX THE PLAYGROUND AND PAINT IT BETTER! & $03 / 05 / 09,21: 58: 14$ \\
\hline$+35387 \times \times \times 4519$ & 2 & KYRA IS A BLOKE. & $03 / 05 / 09,21: 59: 40$ \\
\hline$+35387 \times \times \times 4519$ & 2 & \multicolumn{1}{|l}{} & $03 / 05 / 09,22: 02: 10$ \\
\hline$+35387 \times \times \times 4519$ & 2 & BYE & $03 / 05 / 09,22: 02: 48$ \\
\hline$+35387 \times \times \times 4519$ & 2 & BYE & $03 / 05 / 09,22: 03: 04$ \\
\hline
\end{tabular}


Ananny, M., Strohecker, C. \& K. Biddick (In Press). Shifting Scales on Common Ground: Developing Personal Expressions and Public Opinions. International Journal of Continuing Engineering

Education and Life-Long Learning.

\begin{tabular}{|c|c|c|c|}
\hline Sender's Phone \# & Photo & SMS Text Caption & Date, Time \\
\hline$+35387 \times x \times 9380$ & 3 & gary kennier & $03 / 04 / 29,21: 43: 53$ \\
\hline$+35386 \times \times \times 5794$ & 3 & whats up with snitchy shano & $03 / 05 / 08,21: 53: 11$ \\
\hline$+35386 \times \times \times 5794$ & 3 & hooper \& kenny rules! & $03 / 05 / 08,21: 56: 21$ \\
\hline$+35386 \times \times \times 5794$ & 3 & $\begin{array}{l}\text { shano hooper fisher jackie kiera john mates } \\
\text { all } 3\end{array}$ & $03 / 05 / 08,22: 01: 26$ \\
\hline$+35387 \times \times \times 9212$ & 3 & whats up milleser & $03 / 05 / 09,21: 44: 35$ \\
\hline$+35386 \times \times \times 5794$ & 3 & whats that mean? & $03 / 05 / 09,21: 50: 56$ \\
\hline$+35387 \times x \times 4359$ & 4 & go marie shake your body by gemma & $03 / 05 / 09,21: 40: 07$ \\
\hline$+35387 \times \times x 4519$ & 4 & come along now kiddies... & $03 / 05 / 09,21: 50: 58$ \\
\hline$+35387 \times x \times 9212$ & 4 & aines angels & $03 / 05 / 09,21: 51: 17$ \\
\hline$+35387 \times \times \times 1087$ & 5 & who is she & $03 / 04 / 29,21: 45: 12$ \\
\hline$+35386 \times \times \times 5794$ & 5 & bernie where u been? & $03 / 04 / 29,21: 47: 29$ \\
\hline$+35386 \times \times \times 5794$ & 5 & derek says bernies getting old! & $03 / 05 / 09,21: 53: 01$ \\
\hline$+35387 \times \times \times 9212$ & 5 & bernie is missed & $03 / 05 / 09,21: 54: 25$ \\
\hline$+35386 \times \times \times 5794$ & 5 & derek says bernies getting old! & $03 / 05 / 09,21: 54: 41$ \\
\hline$+35387 \times \times \times 1087$ & 6 & how is its & $03 / 04 / 29,21: 42: 20$ \\
\hline$+35386 \times \times \times 5601$ & 6 & having a party & $03 / 04 / 29,21: 45: 53$ \\
\hline$+35387 \times \times \times 9212$ & 6 & nice & $03 / 05 / 08,21: 49: 33$ \\
\hline$+35386 \times \times \times 5794$ & 6 & cormac sinead wesley gavin mates $\circ 4$ & $03 / 05 / 08,22: 05: 12$ \\
\hline$+35387 \times \times \times 4519$ & 6 & HAVIN' A PARTY! & $03 / 05 / 09,21: 56: 17$ \\
\hline$+35387 \times x \times 9212$ & 7 & a safe place for kids & $03 / 05 / 08,21: 55: 22$ \\
\hline$+35386 \times \times \times 5794$ & 7 & make it more exciting & $03 / 05 / 08,21: 57: 28$ \\
\hline$+35387 \times \times \times 9212$ & 7 & a better place to be0879275332 & $03 / 05 / 08,22: 00: 15$ \\
\hline$+35387 \times x \times 4359$ & 7 & red fence 2 anywhere & $03 / 05 / 09,21: 50: 50$ \\
\hline$+35387 x \times x 4519$ & 7 & $\begin{array}{l}\text { hooper and gavin : best mates. Danny, as } \\
\text { well. }\end{array}$ & $03 / 05 / 09,21: 53: 41$ \\
\hline$+35387 \times x \times 4359$ & 7 & amy ( chantelle friends forever & $03 / 05 / 09,21: 56: 59$ \\
\hline$+35386 \times \times \times 2521$ & 8 & Sunny day, sunny life! & $03 / 05 / 08,21: 53: 47$ \\
\hline$+35387 \times \times \times 4519$ & 8 & gemma is the best lovely looking girl. & $03 / 05 / 09,21: 48: 24$ \\
\hline$+35387 \times \times \times 4359$ & 8 & tracy danika donna rule ok & $03 / 05 / 09,21: 54: 06$ \\
\hline$+35385 \times \times \times 4827$ & 9 & who wants to live here & $03 / 05 / 08,21: 51: 42$ \\
\hline$+35387 \times \times \times 4147$ & 9 & we shall overcome 0877714147 & $03 / 05 / 08,22: 03: 40$ \\
\hline
\end{tabular}

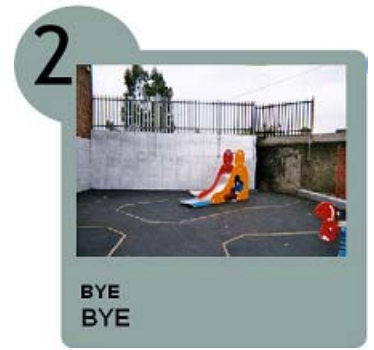

\section{SetB-Photo2 Analytic Narrative}

There are several aspects of this image-text combination to consider: first is to note that the discourse began as a result of an explicit question ("where's that?") and that this conversationstarter was tightly linked to the image. This first text references the pictures content and invites a response that further describes the picture. The subsequent texts focus on the picture, offering both descriptions and opinions of the image scene (the playground is small, somehow related to "Terry", and, at least to one texter, seems to be in a poor state of repair). The conversation ends with a conventional closing but not before a graffiti-like text is inserted in the middle of the playground conversation. This example illustrates text discourse that is: tightly linked to the corresponding visual; conversational in nature; and diverse in form, including both dialogue and graffiti. 
Ananny, M., Strohecker, C. \& K. Biddick (In Press). Shifting Scales on Common Ground: Developing Personal Expressions and Public Opinions. International Journal of Continuing Engineering

Education and Life-Long Learning.

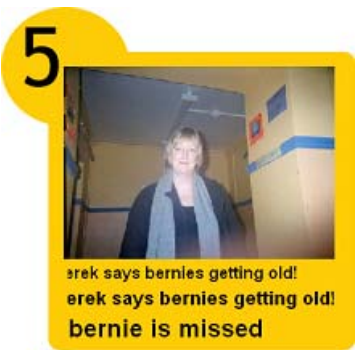

SetB-Photo5 Analytic Narrative

This set is an example of image-text combinations that are tightly linked to a single person. (The person in this photo is a social worker who had left the community a few months earlier.) As with SetB-Photo2, the discourse begins with an explicit question relevant to the image and is followed by texts that both further describe the photo and express opinions about its content: her name is Bernie, she has not been seen recently and is missed by at least one Fatima resident.

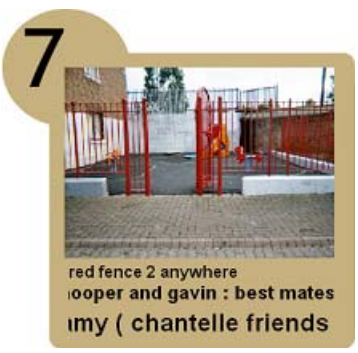

\section{SetB-Photo7 Analytic Narrative}

This set illustrates texts that, like those of SetB-Photo2, is grounded in place and consists of explicit references to the image. However, instead of an explicitly question, the texting began with a direct comment on the image content and followed with further commentary as well as arguably "off-topic" graffiti contributions. This example is grounded in a particular place (the same community playground discussed in SetB-Photo2) and in which a complex opinion of the playground seems to be emerging: it is "safe place for kids" and, although it needs to be "more exciting", it is considered "a better place to be" (we might ask, better than where?) and perhaps a kind of metaphorical starting point ("red fence 2 anywhere").

Figure 6. Image Set C.

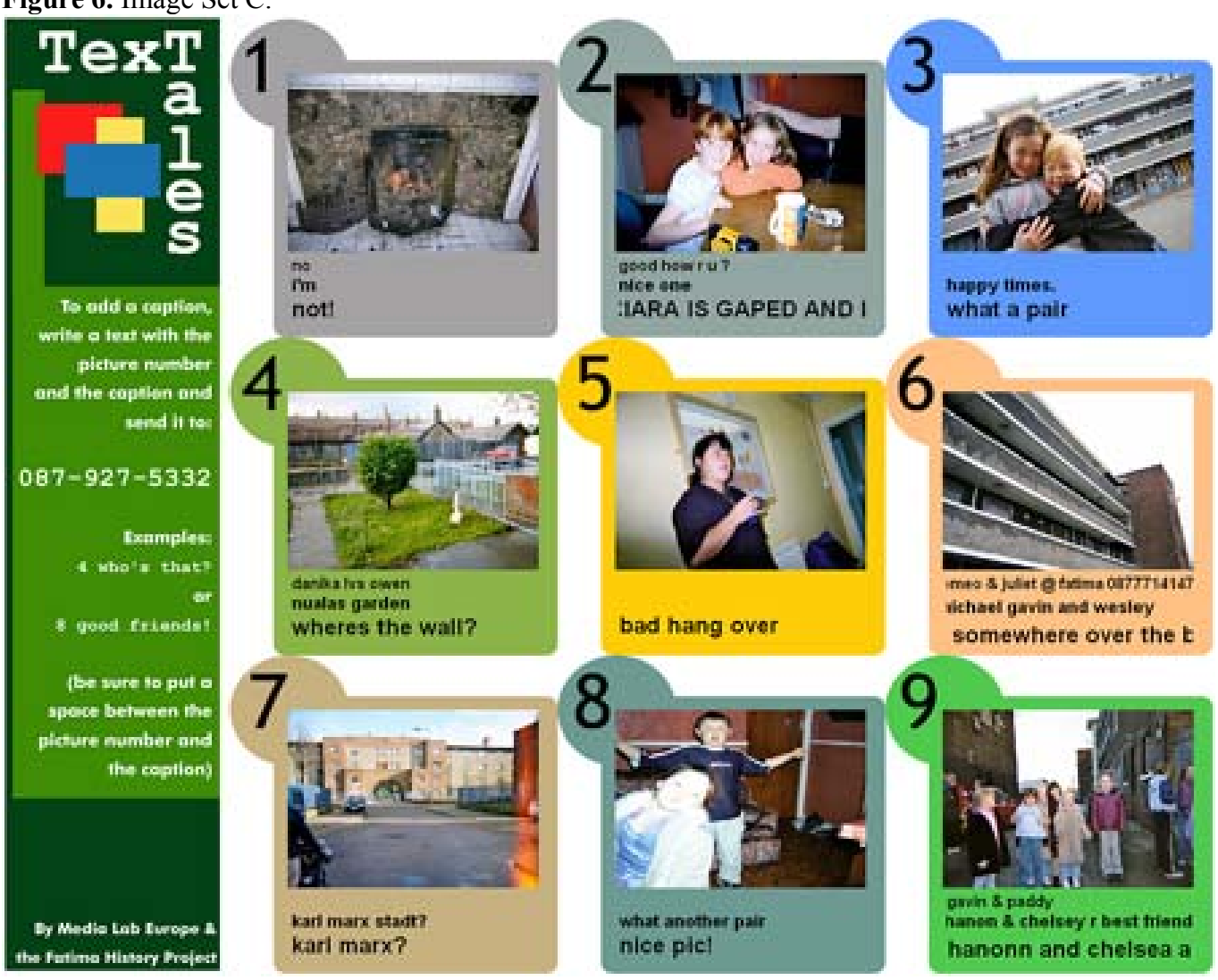


Ananny, M., Strohecker, C. \& K. Biddick (In Press). Shifting Scales on Common Ground: Developing Personal Expressions and Public Opinions. International Journal of Continuing Engineering

Education and Life-Long Learning.

Table 3. All texts sent to Image Set $\mathrm{C}$ over 3 nights of installation, sorted by photo number. Image-text combinations for photos 1,2 and 4 are highlighted and analysed below in more detail.

\begin{tabular}{|c|c|c|c|}
\hline Sender's Phone \# & Photo & SMS Text Caption & Date, Time \\
\hline$+35386 \times \times \times 5794$ & 1 & gavin \& wesley & $03 / 05 / 09,22: 08: 48$ \\
\hline$+35387 \times \times \times 4359$ & 1 & derek is a granddad & $03 / 05 / 09,22: 10: 48$ \\
\hline$+35387 \times x \times 4519$ & 1 & No & $03 / 05 / 09,22: 16: 02$ \\
\hline$+35387 \times x \times 4519$ & 1 & i'm & $03 / 05 / 09,22: 16: 42$ \\
\hline$+35387 \times x \times 4519$ & 1 & not! & $03 / 05 / 09,22: 17: 06$ \\
\hline$+35387 \times \times \times 9380$ & 2 & niggers out & $03 / 04 / 29,21: 50: 02$ \\
\hline$+35387 \times x \times 2895$ & 2 & Howya & $03 / 05 / 08,22: 05: 25$ \\
\hline$+35387 \times x \times 2895$ & 2 & nice one & $03 / 05 / 08,22: 06: 57$ \\
\hline$+35386 \times \times \times 5794$ & 2 & good how $r$ u ? & $03 / 05 / 08,22: 08: 11$ \\
\hline$+35387 \times x \times 4519$ & 2 & CIARA IS GAPED AND PROUD & $03 / 05 / 09,22: 14: 53$ \\
\hline$+35387 \times x \times 1087$ & 3 & happy times. & $03 / 04 / 29,21: 51: 50$ \\
\hline$+35387 \times x \times 9212$ & 3 & what a pair & $03 / 04 / 29,21: 55: 43$ \\
\hline$+35387 \times \times \times 9212$ & 4 & gavin and wesley & $03 / 05 / 08,22: 07: 56$ \\
\hline$+35387 \times x \times 4147$ & 4 & $\begin{array}{l}\text { danika + donna + gemma + gwen + lee } \\
0877714147\end{array}$ & $03 / 05 / 08,22: 10: 38$ \\
\hline$+35387 \times x \times 4359$ & 4 & danika lvs owen & $03 / 05 / 09,22: 06: 21$ \\
\hline$+35387 \times \times \times 9212$ & 4 & nualas garden & $03 / 05 / 09,22: 09: 17$ \\
\hline$+35386 \times \times \times 5794$ & 4 & wheres the wall? & $03 / 05 / 09,22: 20: 12$ \\
\hline$+35386 \times \times \times 5601$ & 5 & bad hang over & $03 / 04 / 29,21: 55: 08$ \\
\hline$+35387 \times x \times 4147$ & 6 & romeo \& juliet @ fatima 0877714147 & $03 / 05 / 08,22: 06: 50$ \\
\hline$+35387 \times x \times 9212$ & 6 & michael gavin and wesley & $03 / 05 / 09,22: 06: 15$ \\
\hline$+35386 \times \times \times 5794$ & 6 & "somewhere over the balcony" & $03 / 05 / 09,22: 23: 17$ \\
\hline$+35387 \times x \times 9212$ & 7 & karl marx stadt? & $03 / 05 / 09,22: 16: 04$ \\
\hline$+35387 \times x \times 4519$ & 7 & karl marx? & $03 / 05 / 09,22: 20: 59$ \\
\hline$+35387 \times x \times 9212$ & 8 & what another pair & $03 / 04 / 29,21: 57: 43$ \\
\hline$+35386 \times \times \times 5794$ & 8 & nice pic! & $03 / 05 / 08,22: 07: 28$ \\
\hline$+35386 \times x \times 5794$ & 9 & gavin \& paddy & $03 / 05 / 08,22: 11: 43$ \\
\hline$+35386 \times \times \times 5794$ & 9 & shanon \& chelsey $r$ best friends & $03 / 05 / 09,22: 18: 16$ \\
\hline$+35386 \times \times \times 8665$ & 9 & shanonn and chelsea are best friends & $03 / 05 / 09,22: 25: 23$ \\
\hline
\end{tabular}

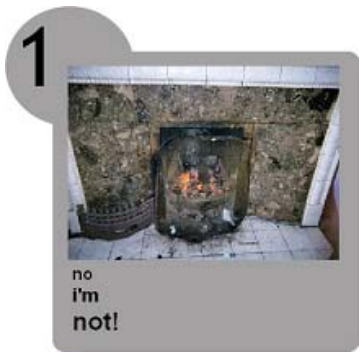

\section{SetC-Photo1 Analytic Narrative}

For this analysis, it is necessary to explain some of the social context around the installation at the moment when these texts were sent. One of the participants was a 12-year old boy, Derek, who was there with his friends but had briefly left the installation. Upon returning, Derek saw under the first image a relatively standard graffiti ("gavin \& wesley") and also a gently teasing text from his friends ("derek is a granddad") - neither of which is relevant to the photo of a fireplace. (Many Fatima apartments do not have central heating, an issue raised several times during the design process with the history group). Derek, knowing that the TexTales only displays the three most recent texts, sent three texts in rapid succession that both refuted the tease and succeeded in occupying all space under the image. Although the nature of the teasing is particular to Derek and his friends, their novel use of TexTales' constraints illustrates fun, game-like aspects of the system as well as novel ways of composing multi-line contributions that dominate the discourse, "taking the conversational floor." Contrast Derek's handling of a playful tease with the more complex issue people struggle with in the next narrative. 
Ananny, M., Strohecker, C. \& K. Biddick (In Press). Shifting Scales on Common Ground: Developing Personal Expressions and Public Opinions. International Journal of Continuing Engineering Education and Life-Long Learning.

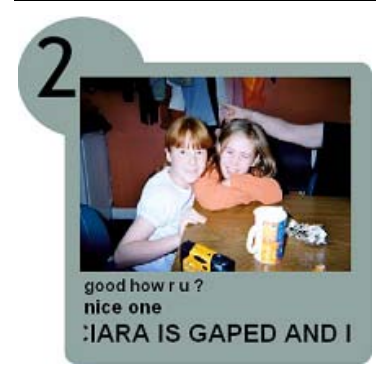

\section{SetC-Photo2 Analytic Narrative}

This example further addresses the issues of censorship and filtering that arose several times during the design process and subsequent installations and, like the example in SetC-Photo1, requires brief explanation of Fatima Mansions' social context. Fatima Mansions is a primarily a Caucasian, Irish-Catholic community that has recently experienced - like much of Dublin, Ireland - a greater number of non-white immigrants travelling through the physical boundaries that have traditionally delimited it from surrounding neighbourhoods. With this understanding and TexTales' support of anonymous graffiti-like texts, it is not surprising that someone sent the text "niggers out" on the evening of April $29^{\text {th }}$. It is interesting to observe, though, that other participants deemed this text to be offensive and replaced it with 3 less controversial submissions. But these subsequent texts were not sent on April $29^{\text {th }}$ - they followed more than one week later, on May $8^{\text {th }}$, during a different installation with a different set of participants.

From observations throughout the design process and on the evenings of April $29^{\text {th }}$ and May $8^{\text {th }}$, the general consensus seemed to be that this text did not represent a widely held opinion. Although the text was displayed anonymously, most people knew who had sent it; the log files show that only one other text earlier on April $29^{\text {th }}$ came from the phone that sent "niggers out" and none at any other times. Beyond the innovative use of the interface to do a kind of editing, there are deeper issues this example illustrates. The reaction among the assembled participants on April $29^{\text {th }}$ was not to engage the "niggers out" texter in dialogue (either through TexTales or through any face-to-face discussion - at least none witnessed by the authors) or to replace the text with any others. On May $8^{\text {th }}$, the audience did take action but only by replacing the offensive message with innocuous text, not engaging either the anonymous author of the offensive text or fellow participants in discussion about the text.

While certainly not representative of an entire community's opinions or discourse habits, this example illustrates several broader points. Namely, as people construct and manage public spheres, we may see not just different perspectives or opinions emerge but we may also see different basic notions of responsibility, ownership or participation: some people may feel little responsibility for discourse not their own and, regardless of their perspective, neglect to comment; others may not agree with other perspectives but yet not feel sufficiently motivated or empowered to counter them; others may not agree but prefer subtle relegation rather than open confrontation; others may agree with perspectives but assent through silence. As we work with people to design and implement discourse spheres, we need to be sensitive to the complex subtleties of discourse practises, especially as people move among stances of participants and observers, authors and audiences, constituents and representatives. 
Ananny, M., Strohecker, C. \& K. Biddick (In Press). Shifting Scales on Common Ground: Developing Personal Expressions and Public Opinions. International Journal of Continuing Engineering

Education and Life-Long Learning.

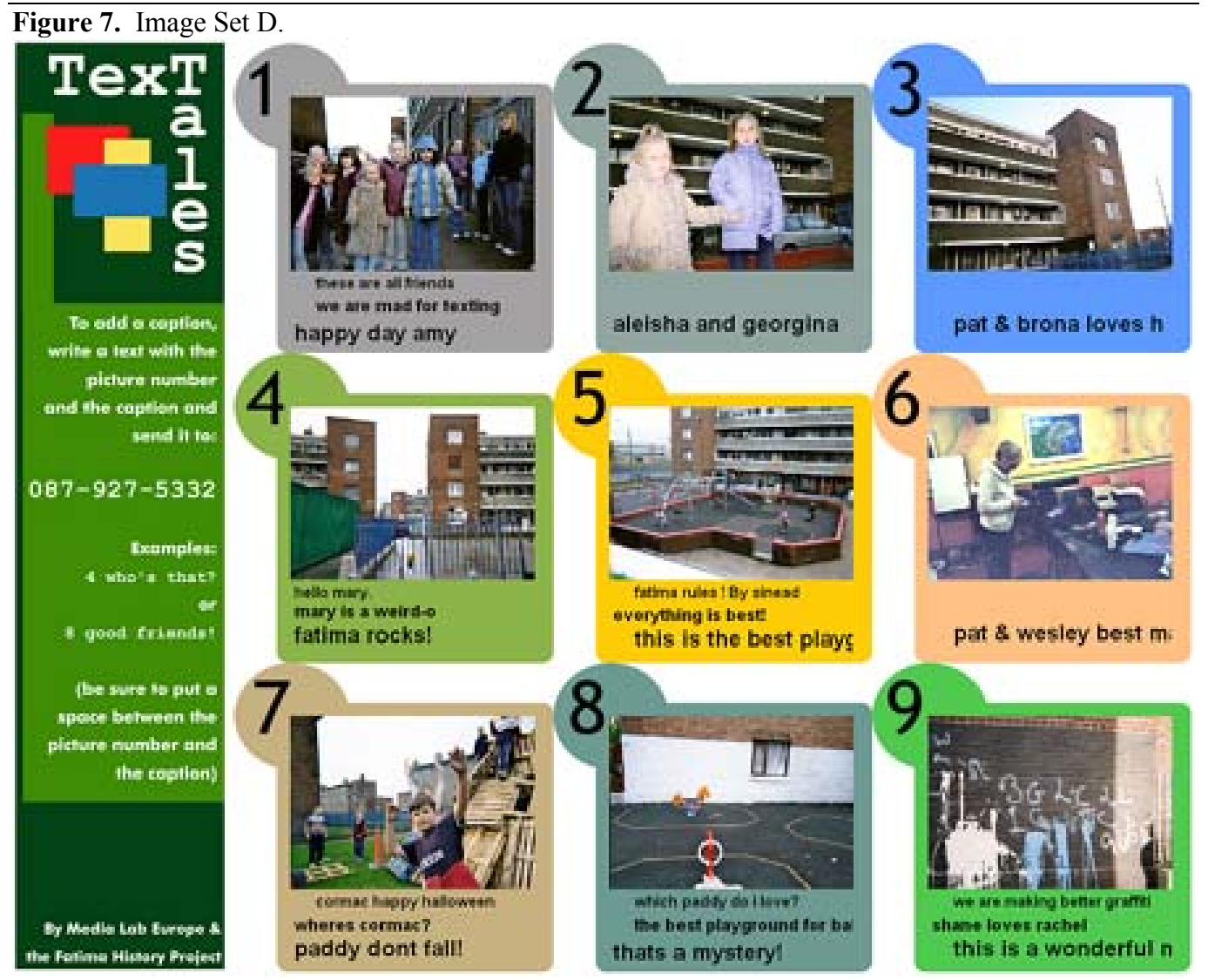

Table 4. All Texts Sent to Image Set D over 3 nights of installation, sorted by photo number. Imagetext combinations for photos 1,2 and 4 are highlighted and analysed below in more detail.

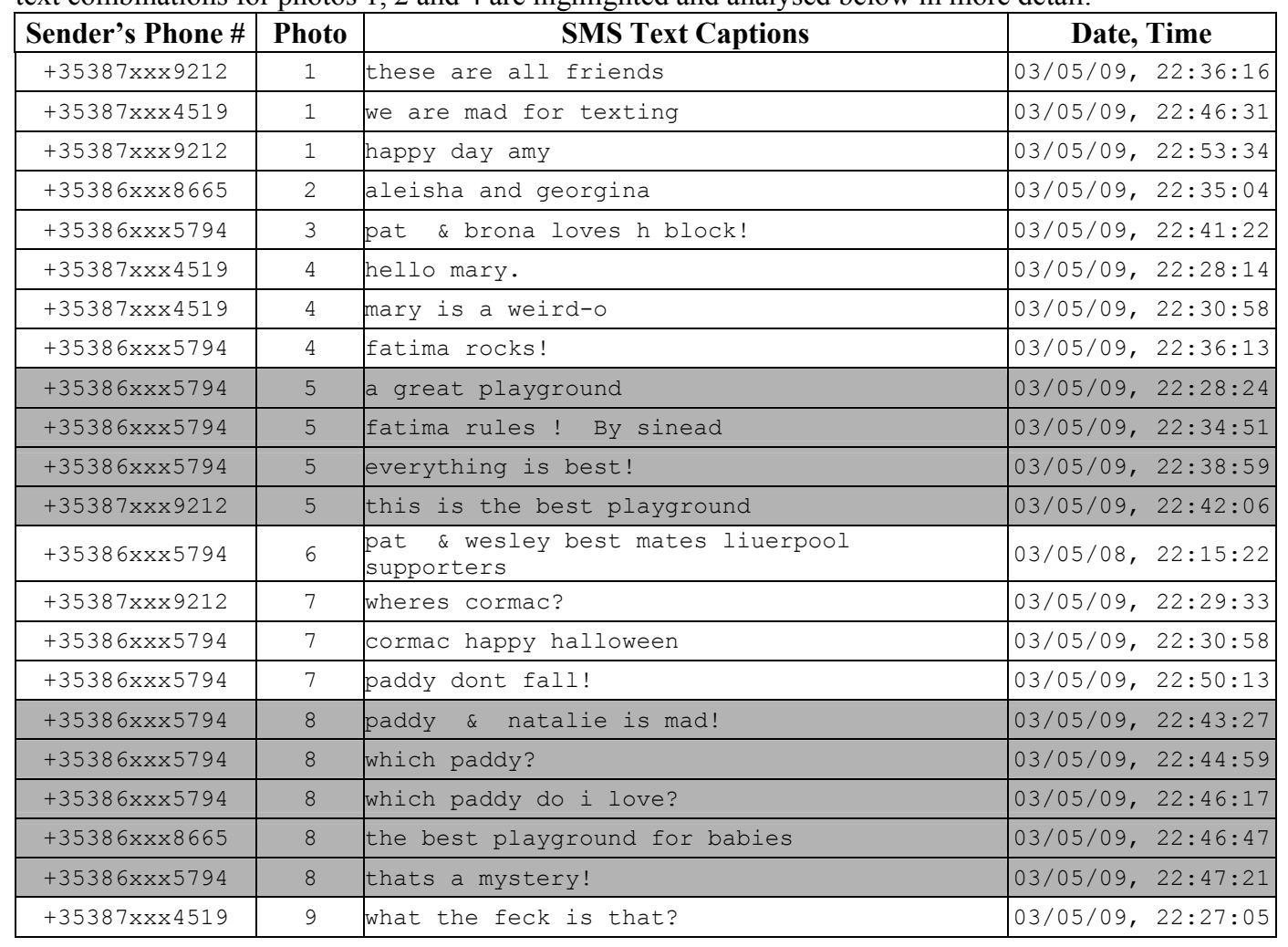


Ananny, M., Strohecker, C. \& K. Biddick (In Press). Shifting Scales on Common Ground: Developing Personal Expressions and Public Opinions. International Journal of Continuing Engineering Education and Life-Long Learning.

\begin{tabular}{|c|c|l|c|}
\hline \hline Sender's Phone \# & Photo & \multicolumn{1}{|c|}{ SMS Text Captions } & Date, Time \\
\hline$+35386 \times \times \times 5794$ & 9 & jackie loves richard & $03 / 05 / 09,22: 33: 10$ \\
\hline$+35387 \times \times \times 4519$ & 9 & we are making better graffiti & $03 / 05 / 09,22: 34: 06$ \\
\hline$+35387 \times \times \times 9212$ & 9 & shane loves rachel & $03 / 05 / 09,22: 47: 32$ \\
\hline$+35386 \times \times \times 8665$ & 9 & this is a wonderful mess & $03 / 05 / 09,22: 51: 04$ \\
\hline
\end{tabular}

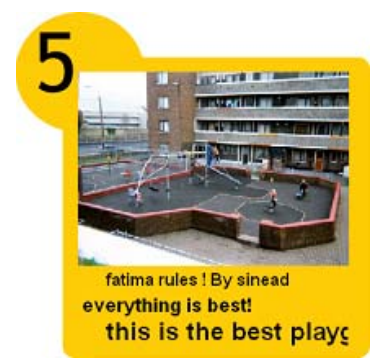

\section{SetD-Photo5 Analytic Narrative}

While not illustrating a style of discourse different than previous image-text combinations, this example demonstrates how opinions might emerge that involve comparing two or more instances of an issue. This picture is of a different, larger playground than the one shown in images SetB-Photo2, SetB-Photo7 or SetD-Photo8. Informal and strong comments made by the History group suggested that this smaller playground, although designed for very small children was rarely used, poorly lit and located near a

particularly rough area. But while the History group seemed to have a clear and unified explanation, TexTales participants seemed more conflicted: participants in this discourse viewed the larger playground as "great" and "the best"; participants in SetB-Photo2 were negative on the small playground calling it "very small" and asking for it to be fixed and painted better; participants in SetB-Photo7 called the small playground "a safe place for kids", said it was "a better place to be" but asked that it be "more exciting"; participants in SetD-Photo8 called the small playground "the best playground for babies".

Even a cursory comparison of two playgrounds reveals conflicting perspectives that may not be captured by statistically significant polls or representative focus groups. In addition to these tools of measurement, we might also focus on the opinion-rich domains of serendipitous commentary and casual discourse.

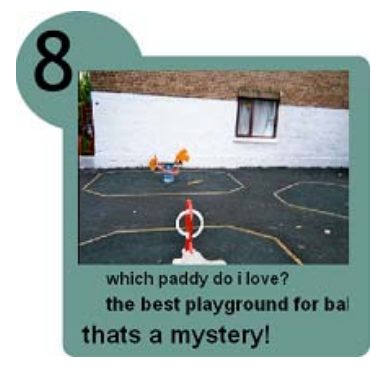

\section{SetD-Photo8 Analytic Narrative}

This example reveals a novel use of the interface that emphasizes the importance of considering the socially situated nature of the discourse. Namely, except for one comment ("the best playground for babies", discussed above), the discourse in this instance seems like a confusing monologue (note that all texts except the playground comment are sent from the same phone and, in this case, by the same person). This is, in fact, one side of a conversation that happened in front of the installation. The initial text "paddy \& natalie is mad!" was sent by Natalie, causing the audience to ask which "paddy" she meant. She smiled and, without responding to them, texted "which paddy?" to TexTales to which audience replied, yes, which 'paddy' do you mean? Again, she refused to answer, instead teasing the audience with the text, "which paddy do i love?" At this point, almost all the audience members were laughing and enjoying the game and finally admitted that they did not know which one she loved. Natalie smiled, texted "thats a mystery!" and went home.

The point of recounting this amusing incident is to demonstrate yet another novel and gamelike use of the interface unintended by the designers but quickly invented by participants. This kind of usage spanning both the interface and the social space - coupled with Derek's real-time editing and multi-line composition; the recurrent and conflicting playground debate; the different ways of reacting to and managing the "niggers out" comment; and the various ways of asking questions of both images and co-participants - demonstrates TexTales' ability to represent a variety of perspectives and a variety of ways to represent perspectives. 
Ananny, M., Strohecker, C. \& K. Biddick (In Press). Shifting Scales on Common Ground: Developing Personal Expressions and Public Opinions. International Journal of Continuing Engineering

Education and Life-Long Learning.

\section{Discussion and Further Work}

We began by arguing that civic discourse is, in a sense, like storytelling and that our principal contribution is a way for people to form new opinions and new ways of forming opinions. Our experiences with TexTales at Fatima mansions were an experiment to develop this approach and an emerging model of citizen-constructed public discourse spheres. Two broad observations characterise the Fatima experience and will help guide future investigations:

\section{Emergent public opinion through an unexpected recurrent theme}

Unlike opinion polls, TexTales aims to be a method of public elicitation and representation in which people construct their own issue categories. Through community-authored photos, a participatory selection and design process, and an open-ended discourse space not restricted to pre-defined topics, our goal was to discover new issues or new opinions on existing issues. We saw one compelling example of this in the numerous and much discussed images of empty playgrounds. People took many images of one particular empty playground, many of the women from the Fatima history group selected these images and, during the installations, people repeatedly offered comments and opinions on the playground. Across several meetings, numerous people confirmed that the city corporation had installed the playground without consulting the community and in a poorly lit area where drug crimes are common. Few children play in the area and the equipment is largely unused. Consistent with the Citizen Journalism framework, this issue emerged repeatedly in a variety of activities (taking photos, selecting photos, captioning photos) and served as a starting point for a much larger discussion of the city corporation's role in the housing development and residents' rights and capacities to manage their own resources. While this issue may have emerged if an external pollster had surveyed the community, with TexTales, the community's arguments and views took a form that was created and developed by residents and that served as starting point for further discussion.

\section{Styles of censorship and ownership}

A variety of styles of censorship and editing emerged as Fatima residents used TexTales. Derek showed a creative and playful understanding of TexTales' three-line display to ensure that his message replaced those of his teasing friends while other residents seemed less sure of how to manage the "niggers out" comment. Immediately after this text was sent, people agreed that it was offensive and ventured informed opinions about who was its author but no one on that night made any attempt to alter its presence on the display or to use TexTales to comment on the remark. Like other kinds of public discourse (e.g. newspapers, town meetings and Internet chat rooms), TexTales may have its own forms of censorship: some explicit and focused on a creating a particular representation (e.g. Derek's playful editing), others more complex involving talking about an offensive remark but avoiding and disowning its representation (e.g. "niggers out"). Regarding ownership of texts, although people usually knew who had sent different texts and texters often announced which captions were theirs, very few people signed their captions. Some people seemed content to "own" their captions in the moment but had little interest in ensuring that their names appeared as authors in the emerging archive. Future work may help to separate and clarify the intertwined properties of anonymity, censorship and ownership. We strive to understand why and how people participate in public discourse spheres and the nature of records created during that participation.

There are several weaknesses to the version of TexTales described here and to how the Fatima activity was framed. Few of the image sets focussed on a specific theme and few of the women from the history group explained why they had chosen or grouped their pictures. While this openness allowed for highly unstructured conversations, in the future we would like to encourage participants to constrain themselves to one or two broad themes and to think of TexTales as an interface with which they can ask questions of their communities. 
Ananny, M., Strohecker, C. \& K. Biddick (In Press). Shifting Scales on Common Ground: Developing Personal Expressions and Public Opinions. International Journal of Continuing Engineering Education and Life-Long Learning.

Although requested, few of the women provided captions to "seed" the discussion of their selected images. This meant that people who first encountered the image sets at the installations had no texts to respond to and were sometimes unsure of what kinds of texts to send. We think that pre-populating the interfaces with caption starters would have likely made it easier for newcomers to participate. Also, although the installation attracted substantial interest within Fatima during the 3 nights, it would be more interesting to arrange for TexTales to be left unattended in a public space for several weeks. A longer timeframe may allow us to see different kinds of interactions. Perhaps people would "drop off" messages for future passers-by, instead of staying at the installation for several hours; or perhaps we would see more community issues emerge as people had more time to think about the form and content of their contributions.

Another limitation of the current system is that, although our goal is to provide a space for real-time intermodal authoring - creating text and image chunks on the fly to represent particular perspectives - this version of TexTales only supports real-time texting, not realtime image composition. Although the images were taken by the community, the amount of time between shooting the image and seeing it appear on TexTales was too great to see any correlations between the kinds of images and texts people contributed or to see the emergence of intermodal authoring styles. Future versions of the software currently under development will support submissions via mobile camera phones.

The experiences described here are the beginnings of rich opportunities for further design and research. For example, one design issue not fully explored is the preparation of the installation's physical scale and its situation in the social space. Early in the TexTales project, we decided to situate the interaction outside and at human scale - as opposed to within a web browser using a keyboard and mouse - from a hunch that, for Fatima Mansions, the kind of social and political phenomena we aimed to investigate were unique to large, physical scales. The fact that few people in the community owned or felt comfortable using standard computers but that many people regularly used SMS text messaging as means of communication was both a design challenge and an opportunity to work with considerations of both physical scale and nomadic communication. Further work is needed to more rigorously consider how the reliance on widely available, pre-existing technologies affects the kind of discourse spheres that we can construct with people and the ways in which people may use these spheres to form public opinions. We are interested in building with people other kinds of forums beyond TexTales and in considering these spaces in relation to different cultures and time periods as well as in relation to a new concept of self-polling.

TexTales' combination of images with associated captions creates a new convention for expressing and forming ideas at personal and collective scales. Through our work with Fatima residents, we have seen how people can become facile and fluent with this "short form", just as people learn to compose Haiku poetry, sonatas and short stories. Unlike most established short forms, TexTales' entries are inherently pluralistic in their use of multiple lines of text and in their combination of texts and image. As we have seen, relations between the lines of text and between texts and image are defining characteristics of the form.

Developing fluency with this form involves becoming deeply familiar with these relationships. We believe this familiarity, facility and fluency constitute a kind of literacy, an "intermodal literacy", of which TexTales is just one example [17].

While this initial experiment with TexTales reveals novel personal expressions and broad patterns of community discourse, left unexplored is a more fine-grained consideration of how images and texts are authored, combined and edited. Indeed, the short form represented here - the SMS text messages, the small thumbnail-like images, the collage-like interface, the rhythm of messages from nomadic participants - all suggest that further work is needed to understand how these new literacies and forms might also work to create new kinds of Constructionist public opinion. 
Ananny, M., Strohecker, C. \& K. Biddick (In Press). Shifting Scales on Common Ground: Developing Personal Expressions and Public Opinions. International Journal of Continuing Engineering

Education and Life-Long Learning.

\section{Conclusions}

We presented here early versions of both a model of civic discourse and a tool for creating public spheres. Our aim is to provide a way for individuals and communities to experiment with trading perspectives, helping them to move among different scales of authorship and to ground their discourse in relation to different people, places and pictures. Our experiences with one community, working with them to create a public installation and archive, have helped us understand characterisations of both broad discourse and personal expressions. By analysing people's civic discourse in relation to both general communication trends and individual, analytic narratives we reveal diversity in both the kinds of perspectives people express in public spheres and in how they manage interactions among these perspectives. TexTales has given us insights into everything from how people in this community censor and edit complex issues to how they play and tease with spontaneous games. Indeed, it is by uncovering and illuminating such serendipitous encounters and these everyday perspectives that we work with people to realise a new kind of civic discourse.

\section{Acknowledgements}

Thanks to Media Lab Europe's Everyday Learning group, especially Brendan Donovan and Jamie Rasmussen for their help building TexTales' architecture, and Niall Winters and Matt Karau for their help with the installations. Special thanks to Kieran Doyle O'Brien, Niall O'Baoille, Irene Ward and, in particular, the women of Fatima History Project for collaboration during the design process. Thanks also to the residents of Fatima Mansions for patiently testing and experimenting with TexTales with us. Finally, thanks to Loyalist College Canada, Frank O'Connor and Jeff Cooper for their guidance through issues of photojournalism and community publishing and to Kodak Canada for donating the disposable cameras. Thanks also to the anonymous reviewers for helpful suggestions and criticism.

\section{References}

1. Alcoff, Linda M. (1995). "The Problem of Speaking for Others.” In Roof, J. \& R. Wiegman (Eds) Who Can Speak? University of Illinois Press: Urbana, IL. Pp. 97-119.

2. Ananny, M. \& C. Strohecker. (2002). Sustained, Open Dialogue with Citizen Photojournalism. Proceedings of Development by Design Conference. Bangalore, India. December 1-2, 2002.

3. Ananny, M, Biddick, K. \& C. Strohecker (2003). Constructing Public Discourse with Ethnographic/SMS "Texts". Proceedings of Mobile HCI 2003, Udine, Italy. Springer-Verlag LNCS series.

4. Asen, R. (2003). The Multiple Mr. Dewey: Multiple publics and permeable borders in John Dewey's theory of the public sphere. Argumentation and Advocacy. Volume 39 (Winter 2003): pp. 174-188.

5. Brignull, H. \& Y. Rogers (2003). Enticing People to Interact with Large Public Displays in Public Spaces. Proceedings of INTERACT'03, Zurich, September 2003.

6. Clark, H. (1993). Arenas of Language Use. University of Chicago Press: Chicago, IL.

7. Dewey, J. (1927/1954). Public and Its Problems. University of Chicago Press: Chicago, IL.

8. Grinter, R.E. \& M. Eldridge. (2001). y do tngrs luv 2 txt msg? In Printz, W. Jarke, M. Rogers, Y., Schmidt, K. $\&$ V. Wulf (Eds.) Proceedings of the Seventh European Conference on Computer-Supported Cooperative Work ECSCW '01, Bonn, Germany. Dordrecht, Netherlands: Kluwer Academic Publishers, pp. 219-238.

9. Grinter, R.E. \& M. Eldridge. (2003). Wan2tlk?: Everyday Text Messaging. Proceedings of CHI 2003, Ft. Lauderdale, Florida. April 5-10, 2003, pp. 441-448.

10. Kafai, Y., and Resnick, M., eds. (1996). Constructionism in Practice: Designing, Thinking, and Learning in a Digital World. Lawrence Erlbaum: Mahwah, NJ.

11. Papert, S. (1980). Mindstorms. Basic Books: New York, NY.

12. Papert, S. \& I. Harel (1991). Situating Constructionism. In Papert, S. \& I. Harel (Eds.) Constructionism. Ablex Publishing: New York, NY.

13. Peters, J.D. (2001). "The Only Proper Scale of Representation": The Politics of Statistics and Stories. Political Communication. 18:433-449. 
Ananny, M., Strohecker, C. \& K. Biddick (In Press). Shifting Scales on Common Ground: Developing Personal Expressions and Public Opinions. International Journal of Continuing Engineering Education and Life-Long Learning.

14. Schudson, M. (1997). Why Conversation is Not the Soul of Democracy. Critical Studies in Mass Communication, 14:297-309.

15. Schudson, M. (1998). The Good Citizen: A History of American Public Life. Free Press: New York, NY.

16. Schudson, M. (2001). Politics as cultural practice. Political Communication, 18:421-431.

17. Strohecker, C. (2003). Constructing Intermodal Literacies. Proceedings of Technology Enhanced Learning, Milan, November 20-21, 2003.

Mike Ananny is a Research Associate in Media Lab Europe's Everyday Learning Group. He's interested in how individuals and communities construct opinions of and for themselves. His current research focusses on new contexts and technologies to support this opinion-building, specifically looking at relationships between mobile technologies as personal authoring devices and large-scale community installations as public discourse spaces. His previous research focussed on tangible interface design for storytelling and very young children's language acquisition. He holds an Honours Bachelors degree in Computer Science and Human Biology from the University of Toronto and a Masters degree in Media Arts and Science from the Massachusetts Institute of Technology. He has worked as an analyst with Nortel Networks, a design consultant with LEGO and is a co-founder of Expresto Software Corporation.

Carol Strohecker is a Senior Scientist and Principal Investigator of the Everyday Learning research group at Media Lab Europe, the European research partner of the MIT Media Lab. She is concerned with how people think and learn, and how objects, artifacts, and technologies can facilitate these processes. Prior to joining MLE in 2001, Dr. Strohecker worked in the United States at MERL - Mitsubishi Electric Research Laboratories and in the Human Interface Group of Sun Microsystems. She earned the PhD of Media Arts and Sciences from the Massachusetts Institute of Technology in 1991, and the Master of Science in Visual Studies from MIT in 1986. She contributed to early efforts in interactive video and has worked extensively in publishing and print media.

Kathleen Biddick, professor of history at the University of Notre Dame, is currently exploring how digital technologies, especially mobile ones, can support the creation of emergent archives. These new intermodal archives are constructed by and help to construct new historical forms of community. She contrasts these emergent archives with historical study of those bureaucratic archives generated over the nineteenth century whose purpose was to produce and maintain architectures of confinement, especially prisons and schools. She collaborates with inmates of these institutions in telling stories about inhabiting today spaces of confinement fabricated in the past. She was a Fulbright Scholar at Media Lab Europe, Dublin in 2002-03. She is currently Director of the Center for Creative Computing at Notre Dame. 